The Third Pole: Journal of Geography

Vol. 18 - 19: 35-44, 2019

DOI: https://doi.org/10.3126/ttp.v18i0.27993

Department of Geography Education,

Central Department of Education, T.U., Kathmandu, Nepal

\title{
FERTILITY BEHAVIOUR AMONG THE BOTE WOMEN OF CHITWAN DISTRICT, NEPAL
}

\begin{abstract}
This paper highlights on fertility behavior of Bote women by calculating the mean children ever born (CEB) focusing the case of Chitawan district. Fertility behavior helps to know about the factors that influence on child birth and indirectly to control population growth. Relevant data were obtained from both primary and secondary sources. Primary data were collected through interview and field observation. For this, a total of 48 newly married women of Bote community between the age of 15 and 49 years were purposefully selected and interviewed. The study showed that the average number of children ever born in the study area is found 2.64. In recent years, mean $C E B$ has been increasing in this community with the increase in age of marriage and education. The CEB also varies by types of occupation. Women involved in diversified occupations have lower fertility rate as compared to women involved in non-diversified traditional occupations. Nowadays, with the increase in level of education, number of women using contraceptive has been increasing. However, still a large section of fertile aged women do not use such birth controlling measures. Awareness programs/ campaigns for increasing education and use of contraceptives and income generating activities further help to improve the situation.
\end{abstract}

Keshav Raj Dhakal ${ }^{1}$

Key words: Fertility, behavior, contraceptive use, children ever born, occupational status

\section{Introduction}

Study of fertility occupies a paramount importance in social science considered fertility as a major component for the growth of population especially in developing countries. Fertility, mortality and migration constitute the three demographic processes that determine the structure, distribution and growth of population. Compared to other demographic processes, fertility is complex because it is affected by multiple factors,

1 Dhakal is an Associate Professor, Department of Geography Education, Central Department of Education, Tribhuvan University, Kathmandu, Email: dhakalkeshav@hotmail.com 
including biological as well as behavioral (MOPE, 2016). Fertility as one of the major components of population change has greater significance than mortality. Most of the developing countries like Nepal, mortality has been declining as compared to fertility. However, the rate of fertility varies greatly among the socio-cultural conditions of the communities as well as countries. Between these two components of population change, the study of fertility is more complicated than mortality (Barclay, 1963). Fertility is the actual reproductive performance of an individual, a couple, a group or population (PRB, 2015).

Fertility behavior is the process of giving birth, which is interacting with the ambient environment; the environment is different in different societies. Within the biological limits of human fertility several social, cultural, psychological as well as economic and political factors are found to operate and these are responsible for determining the levels and differentials of fertility (Bhende \& Kanitkar, 1994). Age at menarche, age at marriage, age at first conception and number of conceptions and live births are some of the biological factors that determine fertility. In contrast to this, the educational status, occupation status, household per capita annual income, family type, and use of birth control measures are the social factors that affect the fertility pattern of a population (Chandiok, Mondal, Mahajan, \& Saraswathy, 2016).

In 1956, Davis \& Blake presented a framework which focused on the industrial mechanism in society and listed eleven intermediate variables through which any factors such as biological, social, and psychological or cultural must operate upon individual fertility (Tuladhar, 1989). These variables affect positively or negatively the fertility of individuals in a society. Such as age into sexual union, permanent celibacy, contraception, sterilization, time between unstable unions, post-widowhood celibacy, foetal mortality from voluntary causes, voluntary abstinence, foetal involuntary mortality, involuntary abstinence and frequency of coitus and inventory sterility (Acharya, 2010). Demographic transition theory states that fertility is high in poor, traditional societies because of high mortality, lack of opportunities for individuals, less advancement and higher economic value of children. These all change with modernization or urban industrialism and individuals, once their viewpoints become reoriented to the change that have taken place, can make use of the new opportunities (Caldwell, Gajnayake, Caldwell \& Caldwell, 1989).

Socio-cultural and economic factors are also equally important to determine fertility and reproduction. The biological and behavioral factors are considered proximate determinants of fertility, on the other hand socio-economic and environmental variables operate to the influence of childbearing rate. Bongaarts \& Potter (1983) identified seven 
proximate determinants of fertility, and divided into two groups: primary and secondary. Primary determinants are marriage pattern, use and effectiveness of contraception, prevalence of induced abortion, post-partum infecundiability and spontaneous intrauterine mortality, waiting time to conception and onset of permanent sterility are in the secondary determinants.

Nepal is a multi-ethnic country inhabited by diverse ethnic communities. With the joint efforts of the Aadibasi Janjati Utthan Rastriya Pratisthan (2001) and Government of Nepal have identified fifty-nine (59) indigenous Nationalities which comprises about 37.2 percent of the total population. Bote has also listed among the 59 ethnic groups who lived in Nepal for centuries. They have their own tradition, culture, customs, language, social norms and values. Bote community has involved in traditional occupations such as hunting, paddling boats and fishing for their livelihoods. They have also used ferries at the various places on the rivers. At present, the Bote community has changed their way of life with the changing environment, modernization, education and contact of other caste and ethnic groups. However, they follow Hinduism with their own deities and beliefs that affect their socio-economic condition including fertility behavior. In this context, this paper attempts to analyze the fertility behavior of Bote women.

\section{Methods and Materials}

This paper is based on both primary and secondary data sources. Primary data were collected from field observation, questionnaire survey and key informant survey. For this purpose, Bote Tole of Bharatpur Metropolitan City, Ward 22, Patihani was selected purposively. Out of 95 married Bote women of reproductive age, 48 respondents were randomly chosen for detailed study. The questionnaire form was used to gather data regarding fertility behavior of that community. The data were categorically divided into two independent and dependent variables. Independent variables are considered as socioeconomic and demographic factors of Bote community. Socioeconomic variables were further classified into three groups: education, occupation, and use of contraceptive. Similarly, demographic variables were also further classified into age of women and age at marriage of respondents. The number of mean children ever born (CEB) has taken as dependent variables. Secondary data were collected from various books, journals and website and official records.

Collected data were tabulated as required. Simple statistical tools like percentage and the mean are used for data analysis. On the basis of analyzing gathered data, a descriptive paper is prepared in order to find out the fertility behavior and demographic characteristics of Bote community. 


\section{Results and Discussions}

\section{History and oral traditions:}

The Bote has listed as the indigenous community with traditional skills as the marginalized and minority group who resided around the Narayani Riverbanks. One of the key informant reported that Bote has two sub divisions between them" Pakho Bote" and "Paani Bote" The name Pakho Bote is derived from Pakho means land in Nepali whereas Paani means water. Their traditional means of livelihood is fishing in the river, the collection of non-timber forest products (fruits, medicinal herbs, vegetables, firewood, fiber, and roofing materials), and the fees (both in cash and kind) generated from ferrying people and merchandise across the river.

Bote are backward community in Nepal. They are marginalized from political mainstream and women have to face lots of burden. One of the Bote society women told that they were considered as inferior and do not get involved in decision making in their home affairs. They do not have private property and have to face domestic violence and brutal beating from their males. There are illiterate and fertility rate is comparatively high.

This study reveals that the number of children who would be born from Bote woman (or per 1,000 women) if she/they passes through the childbearing age who bear children known as fertility. It is measured variously, such as the total fertility rate (TFR), age-specific fertility rates (ASFR). But this paper attempts to analyze the number of children ever born (CEB) of Bote community women in the reproductive age groups. This is one of the measure and indicator for fertility analysis. They are discussed as follows:

Age group of women and mean children ever born (CEB): The term CEB refers to women in a particular age group is the mean number of children born alive to women in that age group. It is computed as the ratio of the number of children born alive to all women in a particular age group to the number of women (https:// www.un.org...) and it can be compared with the demographic and socioeconomic characteristics of married women with 15-49 years in Bote community. The number of children ever born of a particular woman has chosen to measure her lifetime fertility experiences. For this purpose, the following seven age groups of women at five years interval were prepared (Table 1). The result indicates that the number of children ever born of Bote women varies with the age of women (15-49 age groups). The computed mean number of children ever born (CEB) was 2.64, which 
means that newly married Bote women has given higher birth (2.64) as compared to national average 2.12 (NDHS, 2011).

Table: 1 Mean CEB of newly married women age 15-49 years

\begin{tabular}{l|c|c|c|c}
\hline \multirow{2}{*}{ Age group } & \multicolumn{2}{|c|}{ Bote Women } & \multirow{2}{*}{ Live Birth } & \multirow{2}{*}{ Mean CEB } \\
\cline { 2 - 3 } & Number & Percentage & & \\
\hline $15-19$ & 7 & 14.58 & 10 & 1.43 \\
$20-24$ & 8 & 16.67 & 15 & 1.87 \\
$25-29$ & 5 & 10.41 & 13 & 2.60 \\
$30-34$ & 7 & 14.58 & 20 & 2.85 \\
$35-39$ & 9 & 18.75 & 28 & 3.11 \\
$40-44$ & 7 & 14.58 & 25 & 3.20 \\
$45-49$ & 5 & 10.41 & 16 & 3.57 \\
\hline Total & 48 & 100.00 & 127 & 2.64 \\
\hline
\end{tabular}

Source: Field survey, 2018

Table 1 shows the mean CEB of newly married Bote women at the age of 15-49 years. The result indicates that the women in the age group 15-19 years have the lowest level of CEB, it is 1.43 per women. The figure of CEB has gradually been increasing with increasing age of married women. For example, the higher level of per women CEB (3.57) can be observed in 45-49 years age group. This result can be compared with the findings of NDHS (2011), such as the CEB of 15-19 age groups of women were 0.14 and 2.06 for 25-29 age group, as compared to 1.43 and 2.60 respectively in Bote community. It also shows that the mean CEB of Bote women has gradually increased with increasing the age of marriage.

Education and mean children ever born (CEB): Education is an important determinant of fertility in the Bote community. The education of women results in changes in women's health status, family wellbeing, women empowerment and fertility behavior. The level of education directly or indirectly affects the patterns of fertility. The result reveals that the literate women generally have fewer children as compared to illiterate women in this community. One key person told that the educated Bote women can make decisions about the level fertility. It is mainly due to they want relatively less number of children with higher survival rate, and they use more contraceptives than illiterate women (Table 2). Thus, educated women have lower number of child birth. 
Table 2: Relationship between mean CEB and education

\begin{tabular}{l|c|c|c|c}
\hline \multirow{2}{*}{ Literacy Status } & \multicolumn{2}{|c|}{ Bote Women } & \multirow{2}{*}{ Live Birth } & \multirow{2}{*}{ Mean CEB } \\
\cline { 2 - 3 } & Number & Percentage & & 37 \\
\hline Illiterate & 23 & 47.92 & 15 & 3.34 \\
Non formal education & 6 & 12.50 & 22 & 2.50 \\
Primary education & 10 & 20.83 & 10 & 1.43 \\
Secondary education & 7 & 14.58 & 3 & 1.50 \\
Higher education & 2 & 4.16 & 50 & 2.00 \\
\hline Total & 25 & 52.08 & & \\
\hline
\end{tabular}

Source: Field survey, 2018

Table 2 shows the relationship between the mean number of CEB and education of Bote married women. The result indicates that the percentage of literate women is slightly higher $(52.08 \%)$ than illiterate ones $(47.92 \%)$ and their mean CEB was 2.0 and 3.34 respectively. The overall computed mean CEB was 2, however, CEB varies with increasing level of education. For example, 1.43 mean CEB observed for the women who have secondary level education and 2.50 for women having non-formal education. The women with primary and higher levels of education have got CEB 2.22 and 1.5 respectively. The table also portrays that there is an inverse relationship between the level of education and the fertility index. In general, literate women are found more conscious about their family minder and sizes.

Occupation and mean children ever born (CEB): Women's occupation is considered as a major component determining the level of fertility behavior. In recent years, Bote women are involved in diversified occupations such as domestic work, agriculture, business, service and wage labour (Table 3). The figure indicates that the Bote women involved in different occupations have observed different fertility levels. The women involved in service and business have limited time to take care children. Thus, they want fewer children as compared to women who involved in other occupations. The women who involved in better income generating activities have maintained better education, social status, living conditions and it ultimately helps to fertility reduction. 
Table 3: Mean CEB by occupations

\begin{tabular}{l|c|c|c|c}
\hline \multirow{2}{*}{ Occupation } & \multicolumn{2}{|c|}{ Bote Women } & \multirow{2}{*}{ Live Birth } & \multirow{2}{*}{ Mean CEB } \\
\cline { 2 - 3 } & Number & Percentage & & \\
\hline Domestic work & 11 & 22.92 & 44 & 4.00 \\
Agriculture & 12 & 25.00 & 45 & 3.75 \\
Business & 4 & 8.34 & 10 & 2.50 \\
Service & 4 & 8.34 & 10 & 2.50 \\
Wage labor & 5 & 10.42 & 18 & 3.60 \\
\hline Total & 48 & 100.00 & 127 & 2.64 \\
\hline
\end{tabular}

Source: Field survey, 2018

The result also indicates that the women involved in domestic work have the highest CEB (4.00). For example, it is 3.75 for the women who involved in the agriculture sector, and it is followed by 3.60 in wage labor and 2.50 business and service sectors respectively. It can be argued that the women who involved in better income generating occupations have lower level of fertility as compared to traditional occupations.

Age at marriage and mean children ever born (CEB): Age at marriage is also considered as a component to determine the level of fertility of the Bote women. It can be argued that the longer the marital period of women have relatively higher their fertility rate. Because woman who spent the duration of time with her husband after marriage has determined the total number of childbirths in her fertility period. It is also considered as a socio-cultural norm of society. The table shows that the majority of the Bote married women are under the age of 18 years (Table 4). As a result, the fertility rate of Bote women is comparatively high and it contributes to increase the level of fertility in this community. However, Chhetry (1993) found that there was an inverse relationship between age at marriage and level of fertility in Nepal. 
Table 4: Age at marriage and mean CEB

\begin{tabular}{l|c|c|c|c}
\hline \multirow{2}{*}{ Age at marriage } & \multicolumn{2}{|c|}{ Bote women } & \multirow{2}{*}{ Live birth } & \multirow{2}{*}{ Mean CEB } \\
\cline { 2 - 3 } & Number & Percentage & & \\
\hline 14 & 5 & 10.42 & 18 & 3.60 \\
15 & 6 & 12.50 & 19 & 3.16 \\
16 & 6 & 12.50 & 15 & 2.50 \\
17 & 6 & 12.50 & 15 & 2.50 \\
18 & 5 & 10.42 & 15 & 3.00 \\
19 & 6 & 12.50 & 14 & 2.33 \\
20 & 5 & 10.42 & 14 & 2.80 \\
21 & 3 & 6.25 & 6 & 2.00 \\
22 & 2 & 4.17 & 4 & 2.00 \\
23 & 2 & 4.17 & 3 & 1.50 \\
24 & 1 & 2.08 & 2 & 2.00 \\
25 & 1 & 2.08 & 2 & 1.00 \\
\hline Total & 48 & 100.00 & 127 & 2.64 \\
\hline
\end{tabular}

Source: Field survey, 2018

Table 4 shows the women age at marriage of Bote community and mean CEB. The result indicates that about 10.4 percent, Bote women were married at the age of 14 years and their mean CEB was 3.6. It is followed by the marriage age of 15 years $(12.5 \%)$ with mean CEB 3.16 and least by the age of 25 years $(2.1 \%)$ with mean CEB 1 . However, the average mean CEB of Bote community women age at marriage with different ages was 2.64 .

Use of contraceptives and mean CEB: Use of contraceptives has also considered as a determinant of fertility of the Bote married women. WHO report shows that the percentage of contraceptives user married women has been increasing from 9 to 50 percent in the periods of 1965 to 1990 (https:// www.ncbi.nlm.nih.gov/pubmed/1462719). This trend has also noticed in the Bote married women and their level of fertility has been gradually decreasing. The majority of married women reported that they use different types of contraceptives, such as in IUD, oral contraceptives and condoms. They believed that the use of contraceptives has certainly support to reduce level of fertility during their reproductive age. 
Keshav Raj Dhakal / Fertility Behaviour Among the Bote Women of Chitwan District, Nepal

Table 5: Relationship between Mean CEB and use of contraceptives

\begin{tabular}{l|c|c|c|c}
\hline \multirow{2}{*}{ Contraception } & \multicolumn{2}{|c|}{ Bote Women } & \multirow{2}{*}{ Live Birth } & \multirow{2}{*}{ Mean CEB } \\
\cline { 2 - 3 } & Number & Percentage & & \\
\hline User & 22 & 45.83 & 44 & 2.00 \\
Non user & 26 & 54.17 & 83 & 3.19 \\
\hline Total & 48 & 100.00 & 127 & 2.64 \\
\hline
\end{tabular}

Source: Field survey, 2018

Table 5 reveals that the relationship between the Mean CEB and use of contraceptives. Large percentage of contraceptives non-user women $(54.2 \%)$ have observed in the Bote community and their mean number of CEB was found 3.19 while it is only 2.0 for contraceptive users $(45.8 \%)$ women. The findings indicate that there is a positive relationship between the level of fertility and use of contraceptives in the study area.

\section{Conclusions}

The present paper is an attempt to identify the factors affecting the fertility of Bote community. Present age, occupational status, educational status, age at marriage and use of contraceptive are the most important factors that affected the fertility behavior of the women. Education enhances occupational status, implants ideas about the appropriate age for marriage, reduces desire only for son rather than daughter; keeps them busy performing activities for women's personal career and social development. In the same way, women who are confined only to carry out household jobs are considered suitable for producing children. Women who are involved in service and business activities have lower fertility than women with traditional occupations. Use of contraceptives is inversely related to the fertility and this is an important method for decreasing fertility. The fertility level of the study area can be reduced through increasing contraceptive practice. It is found that there exists a relationship between age at marriage of women and the number of children born and surviving. These findings manifest the need for community specific population policy such as need for education for women, income generating opportunities, increasing knowledge and practices towards the use of contraceptive and campaigns to increase age at marriage of women to reduce the fertility in this study area.

\section{References}

Acharya, R.C. (2010). The effect of demographic factors on fertility behavior in Western Terai of Nepal. Economic Journal of Development Issues. 11 \& 12 (1-2). 
Barclay, G. W. (1963). Techniques of population analysis, New York: John Wiley \& Sons Inc.

Bhende A. \&. Kanitkar, T. (1994). Principles of population studies, Bombay: Himalayan Publishing House.

Bongaarts, J. \& Potter, R. (1983). Fertility, biology and behavior: An analysis of the proximate determinants. New York: Academic Press.

Caldwell, J.C., Gajnayake, I., Caldwell B. \& Caldwell, P. (1989). Is marriage delay a multiphasic responses to pressures for fertility decline? The case of Sri Lanka. Journal of Marriage and Family, 51: pp 337-351.

Central Bureau of Statistics (CBS). (2012). National Population and Housing Census, 2011. Kathmandu: CBS.

Chhetry, R. K. (1993). Age at marriage and fertility in Nepal, TathyankGatibidhi (Four Monthly Statistical Bulletin) 14920. Kathmandu: Central Bureau of Statistics. pp 58-62.

Chandiok, K., Mondal, P. R., Mahajan,C. \& Saraswathy, K. N. (2016). Biological and social determinants of fertility behaviour among the Jat women of Haryana State, India. Journal of Anthropology 2016:1-6://dx.doi.org/10.1155/2016/5463168.

Ministry of Population and Environment (2016). Nepal Population Report. Kathmandu: Ministry of Population and Environment.

https://www.un.org/en/development/deasa/population/publications/dataset/fertility/ total-children.asp.

http.//www.ncbi.nlm.nih.gov/pubmed/1462719.

PRB (2015). Population handbook, Washington DC: Population Reference Bureau.

Tuladhar, J. M. (1989). The persistence of high fertility in Nepal, New Delhi: Inter India Publications. 